\title{
Fetal Rehydration Via Intraamniotic Fluid: Contribution of Fetal Swallowing
}

\author{
MICHAEL G. ROSS, DAN J. SHERMAN, PETER SCHREYER, GORE ERVIN, LINDA DAY, AND \\ JIM HUMME \\ Perinatal Research Laboratories, Harbor-UCLA Medical Center, UCLA School of Medicine, \\ Torrance, California 90502 and Assaf Harofe Medical Center, Tel Aviv, Israel
}

\begin{abstract}
Amniotic fluid volume is regulated by a balance of fetal fluid production and resorption. Although fetal swallowing is believed to be a major site of fluid resorption, additional routes of fluid exchange also may contribute. In our present study, five chronically prepared, water-restricted, pregnant ewes with singleton fetuses (128 $\pm 1 \mathrm{~d})$ were rehydrated via an intraamniotic infusion (100 $\mathrm{mL} / \mathrm{h}$ over $90 \mathrm{~min}$ ) of $0.075 \mathrm{M}$ saline. In response to the maternal water restriction, significant increases were noted in maternal and fetal plasma osmolalities $(306.6 \pm 1.2$ to $315.4 \pm 2.4 ; 300.5 \pm 1.5$ to $311.0 \pm 1.6 \mathrm{mosmol} / \mathrm{kg}$, respectively) and arginine vasopressin concentrations (1.9 \pm 0.2 to $22.6 \pm 5.0 ; 1.5 \pm 0.1$ to $8.5 \pm 2.2 \mathrm{pg} / \mathrm{mL}$, respectively). After the intraamniotic infusion, fetal plasma osmolality (311.0 \pm 1.6 to $303.0 \pm 1.2 \mathrm{mosmol} / \mathrm{kg})$ and hematocrit $(36.7 \pm 1.9$ to $33.8 \pm 1.4 \%)$ significantly decreased although there was no change in maternal arterial blood values. Fetal swallowing averaged $0.39 \pm 0.10$ $\mathrm{mL} / \mathrm{min}$ during the basal period and $0.34 \pm 0.17 \mathrm{~mL} / \mathrm{min}$ at maximum dehydration, and decreased significantly to $0.19 \pm 0.07 \mathrm{~mL} / \mathrm{min}$ in response to the intraamniotic infusion. These results indicate the rapid absorption of intraamniotic fluid by the dehydrated ovine fetus, despite the suppression of fetal swallowing. The volume swallowed during and after the intraamniotic infusion was insufficient to account for the observed changes in fetal plasma osmolality and hematocrit. Thus, alternative routes of fluid absorption (i.e. intramembranous flow) likely predominate under conditions of increased fetal plasma to amniotic fluid osmotic gradients. (Pediatr Res 29: 214-217, 1991)
\end{abstract}

\section{Abbreviations}

AVP, arginine vasopression

Amniotic fluid volume and composition during the second half of gestation are regulated by a balance of fetal fluid production (urine and lung fluid) and resorption (fetal swallowing). Fetal urine production and volume swallowed (per kg body wt) greatly exceed normal adult values, resulting in the exchange of amniotic fluid volume every 24 to $48 \mathrm{~h}$ near term $(1,2)$. Each of these sites of fluid exchange may be regulated by fetal endocrine or osmoreceptor systems $(1,2)$. Thus, alterations in fetal body water homeostasis may affect amniotic fluid.

Maternal water restriction significantly alters maternal and

Received December 28, 1989; accepted September 18, 1990.

Correspondence and reprint requests: Michael G. Ross, M.D., Harbor-UCLA Medical Center, UCLA School of Medicine, 1124 West Carson Street, RB \#1, Torrance, CA 90502.

Supported by National Institutes of Health Awards HL-40899 and HD-06335 and Grant 1-1187 from the March of Dimes Birth Defects Foundation. fetal fluid dynamics (3-6). In the pregnant ewe, dehydrationinduced maternal plasma hyperosmolality and hypernatremia are associated with elevated levels of plasma AVP. Fetal plasma osmolality and sodium concentrations parallel maternal values, whereas increases in fetal plasma AVP are gestation-dependent (3). The fetus also may exhibit a relative decrease in plasma volume, glomerular filtration rate, and urine production (3-5). Urinary hyperosmolality, mediated in part by increased plasma AVP, contributes to increased amniotic fluid osmolality (1-3), whereas reduced urine production likely contributes to decreased amniotic fluid volume during dehydration (6).

Intravenous rehydration of the maternal ewe results in the reversal of maternal plasma composition changes and a gradual equilibration of fetal plasma composition, via transplacental fluid flow (5). In view of the potential for fluid exchange between the amniotic cavity and the fetus, we sought to determine if the dehydrated ovine fetus was able to use hypotonic amniotic fluid for rehydration. In addition, we examined the contribution of fetal swallowing to the rehydration of the fetus via amniotic infusion.

\section{MATERIALS AND METHODS}

Animals and Surgery. Five western cross-bred ovine ewes with singleton fetuses at a mean gestational age at the time of surgery of $123 \pm 1 \mathrm{~d}$ (range 122 to $124 \mathrm{~d}$ ) were used in these studies. The amniotic fluid volume and fetal and maternal responses to dehydration in these and one additional animal have been reported separately (6). The animals were maintained under controlled photoperiods of $12 \mathrm{~h}$ light- $12 \mathrm{~h}$ dark $(0600,1800 \mathrm{~h})$ and housed in individual steel study cages before and after operation. Both food (alfalfa pellets) and water were available ad libitum, except for the withholding of food during the 24-h period preceding surgery. Anesthesia was induced by an intramuscular injection of ketamine hydrochloride $(20 \mathrm{mg} / \mathrm{kg})$ plus atropine sulfate $(30 \mu \mathrm{g} / \mathrm{kg})$ and subsequently maintained by a continuous i.v. infusion of ketamine $(15 \mathrm{mg} / \mathrm{kg} / \mathrm{h})$ and locally applied xylocaine (1\%). The uterus was exposed by a midline abdominal incision and a small hysterotomy was performed to provide access to a single fetal hind limb. Polyethylene catheters (inner diameter $1.0 \mathrm{~mm}$, outer diameter $1.8 \mathrm{~mm}$ ) were placed in the dorsal hind limb artery and vein and threaded to the abdominal aorta and inferior vena cava, respectively. A polyethylene catheter (Corometrics Medical System, Wallingford, CT; inner diameter $1.5 \mathrm{~mm}$, outer diameter $3.2 \mathrm{~mm}$ ) was sutured to the distal tip of the fetal hind limb and the uterus was closed in two layers after reposition of the hind limb. Through a second hysterotomy, the fetal left hemithorax was opened in the 8th intercostal space. The peritoneum overlying the esophagus was incised $2 \mathrm{~cm}$ cephalad to the diaphragm and a 4-mm ultrasonic flow probe (Transonic System Inc., Ithaca, NY) was placed loosely around the esophagus. A second amniotic catheter was placed at the level of the fetal neck. In addition, bipolar electro- 
myogram wires (AS632 Cooner Wire, Chatsworth, CA) were inserted on the fetal thyrohyoid muscle, nuchal and thoracic esophagus, and fetal diaphragm. The maternal abdominal wall was closed in layers. The maternal femoral artery and vein were catheterized and all catheters were exteriorized to the maternal flank and placed in a cloth pouch sewn to the ewe's flank.

All animals were provided a minimum of $5 \mathrm{~d}$ postoperative recovery during which time antibiotics were administered and catheters flushed. During the initial $2 \mathrm{~d}$ of recovery, twice daily i.v. injections of gentamicin $(8 \mathrm{mg})$ and oxacillin $(33 \mathrm{mg})$ were administered to the fetus and gentamicin $(72 \mathrm{mg})$, oxacillin (1 $\mathrm{g}$ ), and chloramphenicol ( $1 \mathrm{~g})$ to the ewes. Both maternal and fetal catheters were flushed daily with heparinized saline (10 IU/ $\mathrm{mL}$ ), after which the fetal vascular catheters were filled with sodium heparin $(1000 \mathrm{IU} / \mathrm{mL})$ and sealed with sterile plastic caps. The concentrated heparin solution was completely withdrawn from the fetal catheters each day before any injections.

Experimental Protocol. Maternal and fetal dehydration. The mean gestational age at the initiation of studies was $128 \pm 1 \mathrm{~d}$. On the 1st day of study, basal maternal and fetal arterial blood samples $(1.5 \mathrm{~mL})$ were drawn at -1 and $0 \mathrm{~h}$ before dehydration for measurement of hematocrit and plasma osmolality and sodium, potassium, and AVP concentrations. An additional 0.5 $\mathrm{mL}$ of arterial blood was collected for immediate blood gas analysis. All fetal blood samples were replaced with equivalent volumes of heparinized maternal blood drawn before the study. All maternal samples were replaced with equivalent volumes of saline. Amniotic fluid samples $(1 \mathrm{~mL})$ were drawn for measurement of sodium and potassium concentrations and osmolality. After the basal sampling, maternal water deprivation was initiated for a period of $54 \mathrm{~h}$. Repeat samples of maternal and fetal blood were drawn at timed intervals during the water deprivation (6). Fetal swallowing was recorded for a 4 -h period on each day of the study.

Fetal rehydration (intraamniotic). At $54 \mathrm{~h}$ of water deprivation, warmed $0.075 \mathrm{M}$ saline was infused $(1000 \mathrm{~mL} / \mathrm{h})$ into the amniotic cavity via one amniotic catheter (selected arbitrarily) for $90 \mathrm{~min}$. Animals were monitored for an additional 90-min observation period after the saline infusion. Before, and at 30 , $60,90,120$, and $180 \mathrm{~min}$ after the initiation of the infusion, maternal and fetal blood samples were drawn for measurement of hematocrit, plasma osmolality, and AVP concentration. Maternal and fetal blood pressures and heart rate and amniotic fluid pressure were determined before each blood sample. An amniotic fluid sample was drawn from the second amniotic catheter (not used for the infusion) before and at the conclusion of the infusion. Fetal swallowing (volume) was monitored continuously throughout the rehydration and observation periods.

Analytic Methods. Maternal and fetal heart rate and blood pressure were monitored with a Beckman R-612 physiologic recorder (Beckman Instruments, Inc., Palo Alto, CA) and Statham (Gould Inc., Oxnard, CA) P-23 transducers. Fetal blood pressure was corrected for amniotic fluid pressure. Blood $\mathrm{pH}$, $\mathrm{PO}_{2}$, and $\mathrm{PCO}_{2}$ values were measured at $39^{\circ} \mathrm{C}$ with a Radiometer BM 33 MK2-PHM 72 MKS acid-base analyzer system (Radiometer Co., Copenhagen, Denmark). Plasma and amniotic fluid electrolyte levels were determined by flame photometry (model 143, Instrumentation Laboratory, Watertown, MA). Osmolality was measured by freezing point depression on an Advanced Digimatic Osmometer (model MO, Advanced Instruments Inc., Needham Heights, MA).

Plasma AVP levels were assessed by RIA as previously described (7). The AVP RIA employed in our laboratory is sensitive to $0.8 \mathrm{pg}$ of $\mathrm{AVP} / \mathrm{mL}$ plasma $(0.16 \mathrm{pg} /$ tube). The intraassay and interassay coefficients of variation were 6 and $9 \%$, respectively.

Fetal swallowing was determined by analysis of the esophageal flowmeter signals as described previously (7). Briefly, flow signals were digitized at 50 samples/s using an IBM-compatible microcomputer with a 16-channel, 12-bit analog to digital converter. Asyst software (version 2.1, Asyst Software Technologies, Roch- ester, NY) was customized for data acquisition and off-line analysis. The analysis program identified all positive (cranial to caudal) and negative (caudal to cranial) flows. Each flow velocity waveform was mathematically integrated yielding actual volume per swallow. Net esophageal flow was calculated as positive flow minus negative flow.

Calculations and Statistics. All values are expressed as the mean \pm SEM. Basal values represent the mean of the -1 - and 0 -h samples before dehydration. Time 0 represents maximal (54 h) dehydration, before the intraamniotic infusion. Differences over time were assessed by repeated measures analysis of variance with trends in the data considered statistically significant when the $F$ test yielded a $p$ value less than 0.05 . Differences between time periods were determined using Dunnett's test at a $p$ less than or equal to 0.05 level of significance.

\section{RESULTS}

Maternal dehydration. In response to maternal water deprivation, maternal plasma osmolality $(306.6 \pm 1.2$ to $315.4 \pm 2.4$ mosmol/kg; Fig. 1), sodium concentration (149.2 \pm 1.8 to 155.2 $\pm 1.8 \mathrm{mmol} / \mathrm{L})$, and AVP $(1.9 \pm 0.2$ to $22.6 \pm 5.0 \mathrm{pg} / \mathrm{mL}$; Table 1) increased significantly. Similarly, fetal plasma osmolality $(300.5 \pm 1.5$ to $311.0 \pm 1.6 \mathrm{mosmol} / \mathrm{kg}$; Fig. 1), sodium concentration $(143.8 \pm 2.3$ to $154.8 \pm 4.5 \mathrm{mmol} / \mathrm{L})$, and AVP $(1.5 \pm$ 0.1 to $8.5 \pm 2.2 \mathrm{pg} / \mathrm{mL}$; Table 2) significantly increased. There was no significant change in maternal or fetal hematocrit, $\mathrm{pH}$, $\mathrm{PO}_{2}, \mathrm{PCO}_{2}$, mean blood pressure, or heart rate (Tables 1 and 2 ). A detailed analysis of the time course of maternal, fetal, and amniotic fluid volume responses to dehydration in these and one additional animal has been previously reported (6).

Fetal volume swallowed did not change significantly in response to dehydration $(0.39 \pm 0.10$ to $0.34 \pm 0.17 \mathrm{~mL} / \mathrm{min})$ (Fig. 2). Amniotic fluid osmolality $(276.6 \pm 5.7$ to $310.6 \pm 6.5$ mosmol $/ \mathrm{kg})$ and sodium $(139.8 \pm 4.8$ to $154.0 \pm 5.4 \mathrm{mmol} / \mathrm{L})$ and potassium $(9.2 \pm 1.3$ to $13.4 \pm 2.4 \mathrm{mmol} / \mathrm{L})$ concentrations increased significantly during maternal dehydration.

Fetal rehydration. In response to the intraamniotic infusion of $0.075 \mathrm{M}$ saline, amniotic fluid osmolality (310.6 \pm 6.5 to 214.3 $\pm 2.2 \mathrm{mosmol} / \mathrm{kg}$ ) and sodium concentration (154.0 \pm 5.4 to $122.0 \pm 1.3 \mathrm{mmol} / \mathrm{L}$ ) decreased significantly. Simultaneously, a significant decrease was noted in fetal plasma osmolality $(311.0$ \pm 1.6 to $303.0 \pm 1.2 \mathrm{mosmol} / \mathrm{kg})$ and hematocrit $(36.7 \pm 1.9$ to $33.8 \pm 1.4 \%$ ). Fetal $\mathrm{pH}, \mathrm{PO}_{2}, \mathrm{PCO}_{2}$, plasma AVP, mean blood pressure, heart rate, and maternal cardiovascular or arterial blood values did not change.

Fetal volume swallowed decreased significantly during the intraamniotic saline infusion $(0.19 \pm 0.07 \mathrm{~mL} / \mathrm{min})$ and remained suppressed during the observation period $(0.18 \pm 0.05$ $\mathrm{mL} / \mathrm{min}$ ) (Fig. 2).

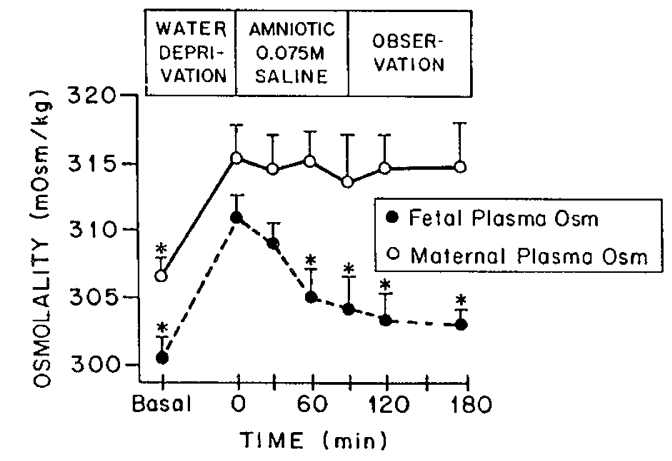

Fig. 1. Maternal and fetal plasma osmolalities during basal period, maximal dehydration (time 0), and during (rehydration) and after (observation) the intraamniotic $0.075 \mathrm{M}$ saline. ${ }^{*} p<0.05$ vs time 0 . 
Table 1. Maternal $(n=5)$ cardiovascular and arterial blood values during dehydration and fetal rehydration

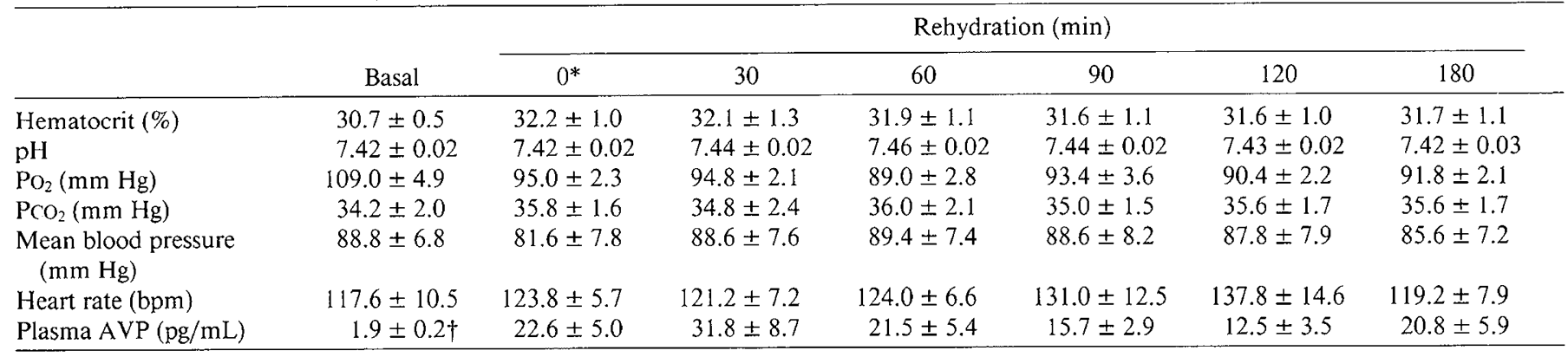

* Time 0 represents maximal dehydration.

$\dagger p<0.05$ vs time 0 .

Table 2. Fetal $(n=5)$ cardiovascular and arterial blood values during dehydration and fetal rehydration

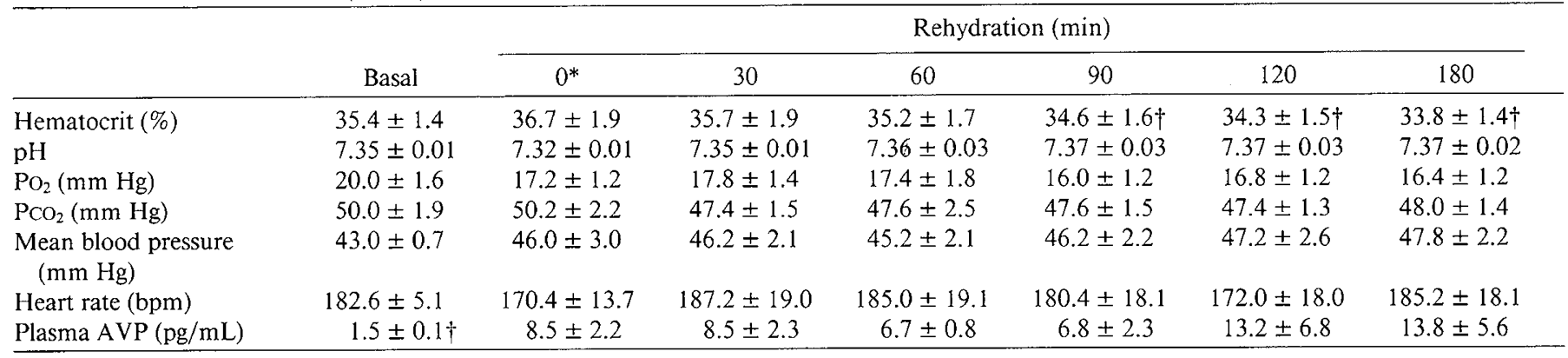

* Time 0 represents maximal dehydration.

$\dagger p<0.05$ vs time 0 .

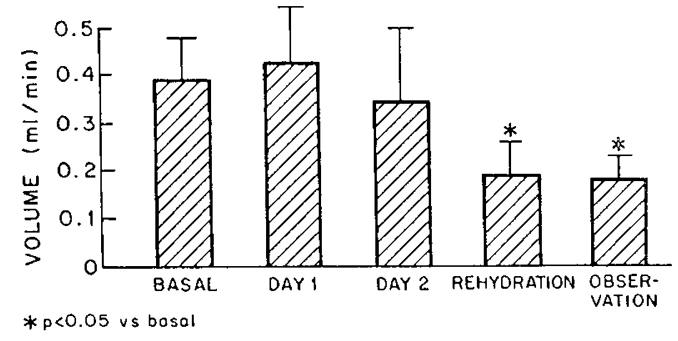

Fig. 2. Fetal volume swallowed (4-h measurements) during dehydration and rehydration via intraamniotic $0.075 \mathrm{M}$ saline. Rehydration refers to the $90-\mathrm{min}$ period of intraamniotic saline infusion. Observation refers to the 90 -min period after the saline infusion. ${ }^{*} p<0.05$ vs basal period.

\section{DISCUSSION}

As described previously (6), maternal water deprivation resulted in significant increases in maternal plasma osmolality and plasma sodium and AVP concentrations. The 9 mosmol $/ \mathrm{kg}$ increase in maternal plasma osmolality is well within the range seen after exercise, thermal dehydration, or mild water deprivation in normal human adults $(8,9)$. Fetal plasma osmolality and sodium and AVP concentrations increased in response to maternal water deprivation (6). The $6 \mathrm{mosmol} / \mathrm{kg}$ difference in maternal and fetal plasma osmolalities is consistent with values measured by vapor-pressure or freezing point depression techniques under aerobic conditions (10). More precise determinations under anaerobic conditions, which reduce plasma carbon dioxide loss, indicate actual plasma osmolality gradients of 2 to 3 mosmol/kg (10). Despite ad libitum feeding, postprandial changes in maternal plasma osmolality (11) also may have contributed to the observed basal osmotic gradient. We recently reported a significant increase in amniotic fluid osmolality and sodium concentration and a decrease in amniotic fluid volume in response to dehydration in these and one additional animal (6). AVP-mediated increased fetal urine osmolality and reduced urine production rates may have accounted for the amniotic fluid changes, although the increased fetal and maternal plasma osmolalities also may have stimulated intramembranous water flow out of the amniotic cavity (12).

In response to intraamniotic $0.075 \mathrm{M}$ saline infusion, amniotic fluid osmolality significantly decreased in association with marked changes in fetal although not maternal plasma osmolality (Fig. 1) and hematocrit (Tables 1 and 2). Fetal plasma osmolality decreased most rapidly during the initial $60 \mathrm{~min}$ of the infusion, with a continued although more gradual decrease over the remaining $120 \mathrm{~min}$. As maternal plasma osmolality did not change, the decrease in fetal plasma osmolality occurred despite a continued, and likely augmented, fetal to maternal transplacental water flow. Concomitantly, fetal hematocrit significantly decreased to values below those before maternal dehydration. It is unlikely that changes in fetal hematocrit were secondary to blood sampling, as each fetal sample was replaced with an equivalent volume of maternal blood. Nor was there evidence of fetal hemolysis in response to the intraamniotic infusion of $0.075 \mathrm{M}$ saline. Thus, as evidenced by the decrease in fetal hematocrit and plasma osmolality, fetal blood volume apparently increased as a result of the fetal absorption of water from the amniotic cavity. These findings differ from the results of Gilbert and Brace (12), who observed decreased fetal blood volume after an intraamniotic infusion of distilled water to euhydrated sheep. However, these investigators noted significant fetal plasma hypoosmolality and hemolysis, which may have contributed to fetal vasoconstriction and blood volume contraction (12).

Fetal plasma AVP levels did not change in response to the intraamniotic rehydration. In a previous study, maternal i.v. rehydration resulted in decreased fetal plasma osmolality but a continued elevation of plasma AVP (5). As dehydration-induced fetal blood volume contraction was not normalized by maternal rehydration in the prior study, it suggested that AVP secretion may have continued in response to persistent volume stimuli. However, the suggestion of increased plasma volume in response to intraamniotic rehydration indicates that AVP secretion is not rapidly suppressed by normalization of either plasma osmolality or volume. In response to rehydration, adult AVP secretion appears to be suppressed by a combination of oral stimuli, gastric 
distension, and plasma composition changes (13). It is unknown whether similar mechanisms are operable during fetal life.

The basal fetal swallowing rate $(0.39 \pm 0.10 \mathrm{~mL} / \mathrm{min})$ extrapolates to $560 \mathrm{~mL} / \mathrm{d}$, a volume consistent with previous determinations using electromagnetic flowmeter analysis (14) or tracer dilution (15). Fetal volume swallowed did not change significantly on $\mathrm{d} 1$ or $\mathrm{d} 2$ of maternal water deprivation, despite the $10 \mathrm{mosmol} / \mathrm{kg}$ increase in plasma osmolality. Previously, we demonstrated a significant stimulation of fetal swallowing activity and volume in response to an i.v. injection of hypertonic saline to the fetus (16), indicating an intact ovine "thirst" mechanism during the last third of gestation. Fetal plasma osmolality acutely increased by $14 \mathrm{mosmol} / \mathrm{kg}$ in the earlier study, suggesting that the plasma osmolality threshold for fetal thirst stimulation may be greater than that achieved in the present study. Alternatively, the rapidity of change in plasma osmolality or sodium concentration may influence the stimulation of swallowing.

Fetal volume swallowed significantly decreased by greater than $50 \%$ in response to the intraamniotic infusion and remained suppressed throughout the recovery period. The rapid reduction in fetal plasma osmolality and the expanded intravascular volume may have contributed to the suppression of thirst and swallowing. In view of the decreased volume swallowed, one may question whether fetal swallowing could explain the plasma composition changes noted in response to the intraamniotic infusion. Fetal swallowing averaged $0.18 \mathrm{~mL} / \mathrm{min}$, or a total of $33 \mathrm{~mL}$ during and after the intraamniotic infusion. One may assume an approximate osmolality of swallowed amniotic fluid of $214 \mathrm{mosmol} / \mathrm{kg}$ (after the intraamniotic infusion), although this may have returned toward basal values by the completion of the study. In a previous study (17), we demonstrated a significant decrease in fetal plasma osmolality in response to fetal intraruminal infusions ( $140 \mathrm{~mL}$ over $60 \mathrm{~min}$ ) of distilled water. Despite more than a 4-fold difference in volume swallowed in the present study $(33 \mathrm{~mL})$ and marked differences in osmolalities (214 versus $5 \mathrm{mosmol} / \mathrm{kg}$ ), similar decreases in fetal plasma osmolality were noted in both studies.

Thus, in the present study, it is unlikely that fetal swallowing represented the sole site of fetal fluid resorption. Although the fetal gastrointestinal tract is believed to be the major site of fetal resorption of amniotic fluid, it may not be the sole route. Human fetuses with an inability to swallow (esophageal atresia, anencephaly) often, although not invariably, develop polyhydramnios $(18,19)$. Furthermore, esophageal ligation in several animal models has resulted in transient or no increase in amniotic fluid volume $(20,21)$. As an alternate route of fluid exchange, intramembranous water flow may occur in response to an increased osmotic gradient from fetal or maternal plasma to amniotic fluid (12). The highly vascular ovine chorion offers a surface area for water exchange sufficient to impact the fetus (22). Although water diffusion into the maternal plasma may potentially occur, the large maternal volume of distribution may impair the detection of this exchange.

In summary, the intraamniotic $0.075 \mathrm{M}$ saline infusion to dehydrated ewes significantly decreased fetal plasma osmolality and hematocrit. However, fetal swallowing was suppressed during rehydration, suggesting alternative routes of fetal-amniotic fluid exchange.

\section{REFERENCES}

1. Brace RA 1986 Amniotic fluid volume and its relationship to fetal fluid balance: review of experimental data. Semin Perinatol 10:103-112

2. Ervin MG, Ross MG 1989 Regulation of amniotic fluid volume and composition. In: Fetal and Neonatal Body Fluids: The Scientific Basis for Clinical Practice. Perinatology Press, Ithaca, New York, pp 117-133

3. Bell RJ, Congiu M, Hardy KJ, Wintour EM 1984 Gestation-dependent aspects of the response to the ovine fetus to the osmotic stress induced by maternal water deprivation. Q J Exp Physiol 69:187-195

4. Stevens AD, Lumbers ER 1985 The effect of maternal fluid intake on the volume and composition of fetal urine. J Dev Physiol 7:161-166

5. Ross MG, Sherman DJ, Ervin MG, Castro R, Humme J 1988 Maternal dehydration-rehydration: fetal plasma and urinary responses. Am J Physiol 255:E674-E679

6. Schreyer P, Sherman DJ, Ervin MG, Day L, Ross MG 1990 Maternal dehydration: impact on ovine amniotic fluid volume and composition. J Dev Physiol (in press)

7. Ross MG, Sherman DJ, Ervin MG, Day L, Humme J 1990 Fetal swallowing: response to systemic hypotension. Am J Physiol 258:R130-R134

8. Van Beaumont W, Underkofler S, Van Beaumont S 1981 Erythrocyte volume plasma volume, and acid-base changes in exercise and heat dehydration. $\mathrm{J}$ Appl Physiol 50:1255-1262

9. Costill DL, Fink WJ 1974 Plasma volume changes following exercise and thermal dehydration. $\mathbf{J}$ Appl Physiol 37:521-525

10. Armentrout T, Katz S, Thornburg KL, Faber JJ 1977 Osmotic flow through the placenta barrier of chronically prepared sheep. Am $J$ Physiol 233(4):H466-H474

11. Mellor DJ, Slater JS 1973 The composition of maternal plasma and foetal urine after feeding and drinking in chronically catheterized ewes during the last two months of pregnancy. J Physiol 234:519-531

12. Gilbert WM, Brace RA 1989 The missing link in amniotic fluid volume regulation: intramembraneous absorption. Obstet Gynecol 74:748-754

13. Thompson CJ, Burd JM, Baylis PH 1986 Acute suppression of plasma vasopressin and thirst after drinking in hypernatremic humans. Am J Physiol 252:1138-1142

14. Bradley RM, Mistretta CM 1973 Swallowing in fetal sheep. Science 179:10161017

15. Tomoda S, Brace RA, Longo LD 1985 Amniotic fluid volume and fetal swallowing rate in sheep. Am J Physiol 249:R133-R138

16. Ross MG, Sherman DJ, Ervin MG, Day L, Humme J 1989 Stimuli for fetal swallowing: systemic factors. Am J Obstet Gynecol 161:1559-1565

17. Sherman DJ, Ervin MG, Hobel CJ, Humme J, Gimpel J, Ross MG 1988 Plasma and urine responses to gastric infusions in the ovine fetus. Clin Res $36: 235 \mathrm{~A}$ (abstr)

18. Pritchard JA 1965 Deglutition of normal and anencephalic fetuses. Obstet Gynecol 25:289-297

19. Nichols J, Schrepfer R 1966 Polyhydramnios in anencephaly. JAMA 197:121123

20. Minei LJ, Suzuki R 1976 Role of fetal deglutition and micturition in the production and turnover of amniotic fluid in the monkey. Obstet Gynecol 48:177-181

21. Wintour EM, Barnes A, Brown EH, Hardy KJ, Horacek I, McDougall JG, Soggins BA 1978 Regulation of amniotic fluid volume and composition in the ovine fetus. Obstet Gynecol 52:689-698

22. Makowski EL, Meschia G, Droegemueller W, Battaglia FC 1968 Measurement of umbilical arterial blood flow to the sheep placenta and fetus in utero. Circ Res 23:623-631 